\title{
LXR promotes the maximal egress of monocyte-derived cells from mouse aortic plaques during atherosclerosis regression
}

\author{
Jonathan E. Feig, ${ }^{1}$ Ines Pineda-Torra, ${ }^{2}$ Marie Sanson, ${ }^{1}$ Michelle N. Bradley, ${ }^{3}$ \\ Yuliya Vengrenyuk, ${ }^{1}$ Dusan Bogunovic, ${ }^{4}$ Emmanuel L. Gautier, ${ }^{5}$ Daniel Rubinstein, ${ }^{1}$ \\ Cynthia Hong, ${ }^{3}$ Jianhua Liu, ${ }^{5}$ Chaowei Wu, ${ }^{2}$ Nico van Rooijen, ${ }^{6}$ Nina Bhardwaj, ${ }^{4}$ \\ Michael J. Garabedian, ${ }^{2}$ Peter Tontonoz, ${ }^{3}$ and Edward A. Fisher ${ }^{1}$ \\ 1Department of Medicine, Division of Cardiology, and 2Department of Microbiology, New York University School of Medicine, \\ New York, New York, USA. ${ }^{3}$ Howard Hughes Medical Institute, Department of Pathology and Laboratory Medicine, \\ UCLA, Los Angeles, California, USA. ${ }^{4}$ Department of Pathology, New York University School of Medicine, New York, New York, USA. \\ ${ }^{5}$ Department of Gene and Cell Medicine and Immunology Institute, Mount Sinai School of Medicine, \\ New York, New York, USA. ${ }^{6}$ Vrije Universiteit, Amsterdam, Netherlands.
}

\begin{abstract}
We have previously shown that mouse atherosclerosis regression involves monocyte-derived $\left(\mathrm{CD}^{+} 8^{+}\right)$cell emigration from plaques and is dependent on the chemokine receptor CCR7. Concurrent with regression, mRNA levels of the gene encoding $L X R \alpha$ are increased in plaque $\mathrm{CD68}^{+}$cells, suggestive of a functional relationship between LXR and CCR7. To extend these results, atherosclerotic Apoe $e^{-/}$mice sufficient or deficient in CCR7 were treated with an LXR agonist, resulting in a CCR7-dependent decrease in plaque $\mathrm{CD}^{2} 8^{+}$cells. To test the requirement for LXR for CCR7-dependent regression, we transplanted aortic arches from atherosclerotic Apoe ${ }^{-/-}$ mice, or from $A p o e^{-/-}$mice with BM deficiency of LXR $\alpha$ or LXR $\beta$, into WT recipients. Plaques from both LXR $\alpha-$ and LXR $\beta$-deficient $A p o e^{-/-}$mice exhibited impaired regression. In addition, the $\mathrm{CD68}^{+}$cells displayed reduced emigration and CCR7 expression. Using an immature DC line, we found that LXR agonist treatment increased Ccr 7 mRNA levels. This increase was blunted when $L X R \alpha$ and LXR $\beta$ levels were reduced by siRNAs. Moreover, LXR agonist treatment of primary human immature DCs resulted in functionally significant upregulation of CCR7. We conclude that LXR is required for maximal effects on plaque $\mathrm{CD68}^{+}$cell expression of CCR7 and monocyte-derived cell egress during atherosclerosis regression in mice.
\end{abstract}

\section{Introduction}

Atherosclerosis is the leading underlying cause of death worldwide (1). Absolute risk for cardiovascular disease rises with age because of the progression of coronary atherosclerosis (2-6). To date, the major intervention to delay or halt disease progression has been the use of statins to lower LDL (7). These drugs, however, have modest effects on plaque burden and risk, as reflected, for example, by the small degree of regression seen in the REVERSAL $(8,9)$ and ASTEROID $(10)$ studies, and by the still-substantial rates of heart attacks occurring in the treatment arms of largescale clinical trials (e.g., ref. 11). Thus, by understanding the factors that lead to plaque regression, better treatment options beyond current therapies may be developed for many at risk, who already carry a heavy plaque burden.

In spite of the clinical desirability to achieve regression, research into the factors that may be mediating this process has been hampered by the relative paucity of appropriate animal models. The similarities between atherosclerosis progression in humans and mice deficient in either apoE (Apoe $\mathrm{e}^{-/} ;$refs. 12,13$)$ or the LDL receptor $\left(\mathrm{Ldll}^{-/} ;\right.$; ref. 14) suggest that molecular mechanisms underlying regression in these mouse models could be relevant to the reduction in plaque burden in the human population $(15,16)$.

Conflict of interest: N. Bhardwaj owns stock in Dendreon, Pfizer, and Bristol-Myers Squibb and is a coinventor on patents related to human DC production and function. E.A. Fisher received an honoraria from Merck.

Citation for this article: J Clin Invest. 2010;120(12):4415-4424. doi:10.1172/JCI38911.
Regression studies in mice have indeed been undertaken, with some modest successes reported (17-21). To introduce a more robust model, we developed an approach in which transplantation of either an atherosclerosis-containing thoracic aortic segment (22) or an aortic arch segment (23) from $\mathrm{Apoe}^{-/-}$mice to WT recipient mice leads to the dyslipidemia being corrected rapidly and indefinitely. Under these conditions in the WT mouse, regression is soon apparent (as judged by plaque content of cells positive for CD68, a standard marker of macrophages and foam cells; ref. 24), whereas in the Apoe ${ }^{-/}$recipient, further progression is evident $(22,25-27)$.

Notably, the decrease in $\mathrm{CD} 68^{+}$cell content is attributable to emigration of these cells from plaques to regional and systemic LNs under regression conditions (i.e., in the WT recipient; refs. $25,27)$. These cells may be either DCs or macrophages $(28)$. DCs are generally more efficient in emigrating to LNs through lymphatics than are macrophages, and the cells that emigrate from plaque express markers, such as CD11c and MHC II, that are found on DCs as well as on some macrophages. Because the migration of either DCs or monocyte-derived cells resembling both DCs and macrophages $(29,30)$ to LNs through lymphatics appears (based on the current literature) to absolutely require the chemokine receptor CCR7 and/or CCR7 ligands (31-34), we hypothesized that CCR7 may be induced in $\mathrm{CD}^{+} 8^{+}$cells under regression conditions to promote egress from plaques, regardless of whether these cells developed into bona fide DCs or lymphtrafficking cells with only some features of DCs (28-30). Indeed, we found a selective increase in mRNA and protein expression 


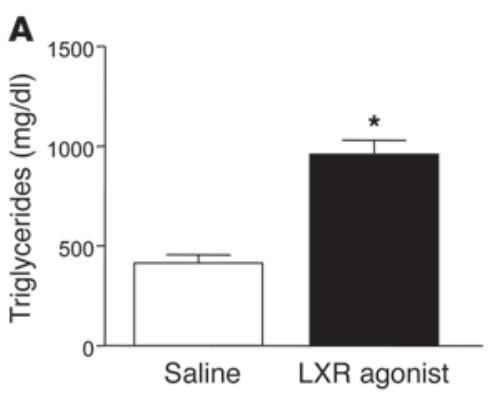

B

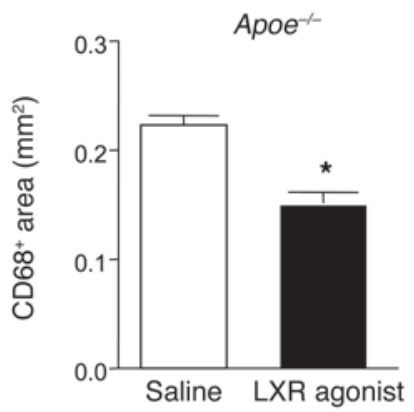

$\mathbf{E}$

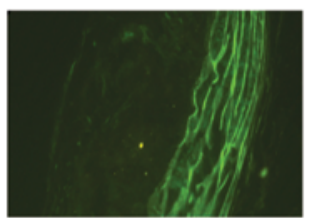

Saline
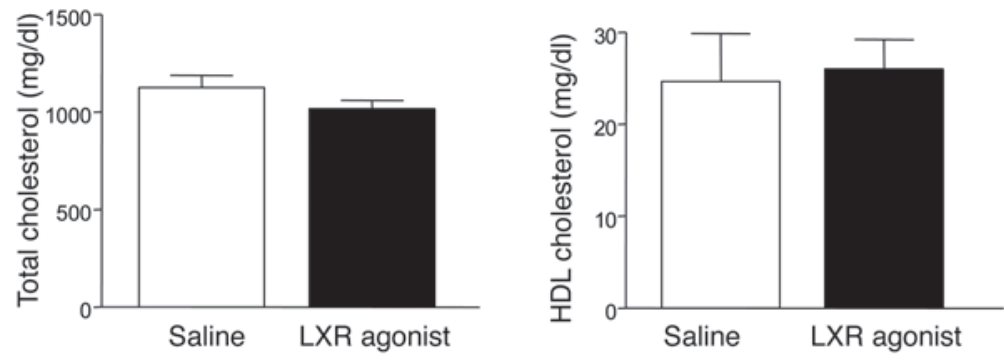

C

D
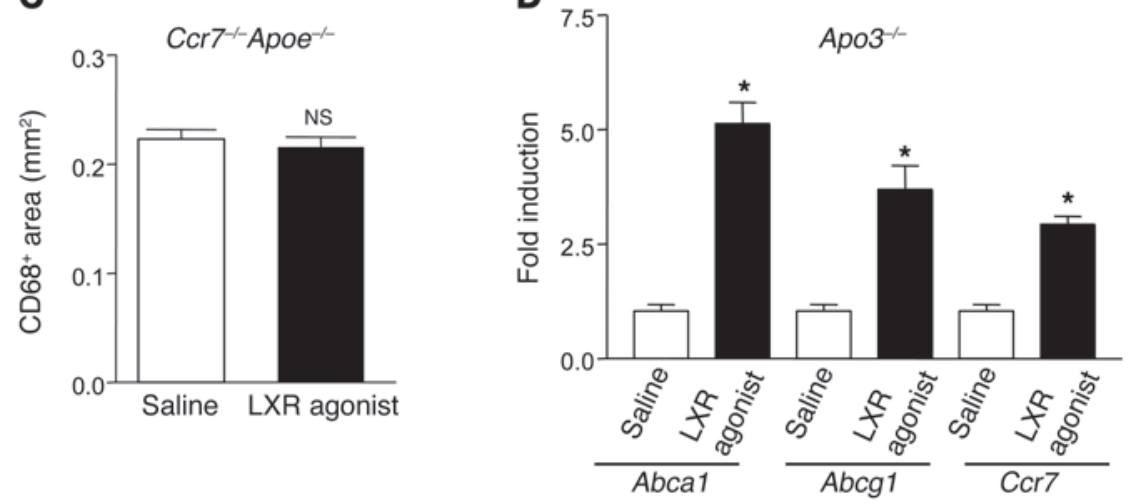

$\mathbf{F}$

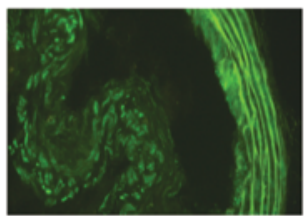

LXR agonist

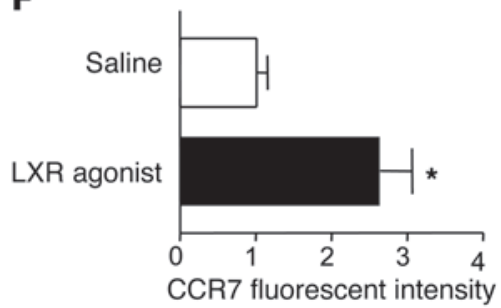

Figure 1

Activation of LXR increases CCR7 expression in atherosclerotic lesions and promotes plaque regression. Apoe ${ }^{-/-}$mice $(n=30)$ were placed on Western diet for 16 weeks, after which they were injected intravenously with either LXR agonist or saline daily for 2 weeks. At the end of the treatment period, plasma lipids were measured $(\mathbf{A})$, and lesional $\mathrm{CD} 68^{+}$cell content was determined (B). Ccr7 $7^{-l-}$ Apoe ${ }^{-/-}$mice $(n=7)$ were treated as above with LXR agonist, and the $\mathrm{CD}_{68}{ }^{+}$content of the atherosclerotic lesions was determined (C). In addition, $\mathrm{CD}^{2} 8^{+}$cells from $A p o e^{-/-}$mice were laser captured and the isolated RNA used for qRT-PCR measurements of the indicated mRNAs (normalized to Ppia, which encodes cyclophilin A) (D). The increase in Ccr7 mRNA in samples from agonist-treated mice was confirmed at the protein level by immunostaining ( $E$ and $F$; original magnification, $\times 400$ ). The striped green background signal is due to autofluorescence from the internal elastic lamina from the medial layer of the artery. ${ }^{*} P<0.05$ versus saline.

of CCR7 within plaque $\mathrm{CD}^{2} 8^{+}$cells from the regression environment and went on to show a functional role for CCR7 ligands in regression (27). We also observed induction of mRNA from the gene encoding liver $\mathrm{X}$ receptor $\alpha(\operatorname{LXR} \alpha)$ in foam cells in the regression environment (27). This raised the possibility that LXR and CCR7 are functionally related in atherosclerosis regression, which is a focus of the present study.

LXRs - specifically, LXR $\alpha$ and LXR $\beta$ (encoded by Nr1b3 and $N r 1 b 2$, respectively) - are nuclear hormone receptors that play key roles in maintaining cholesterol homeostasis in macrophages, primarily by regulating multiple components of the reverse cholesterol transport (RCT) pathway (35-37). Taking note of a prior report that an LXR agonist can promote regression in $\mathrm{Ldlr}^{-/}$mice (38), we hypothesized that LXR is also atheroprotective through an ability to induce CCR7 gene expression and stimulate CD68 ${ }^{+}$ cell migration. Using a number of systems and approaches, we obtained multiple independent lines of evidence that all point to this being the case. Furthermore, our data strongly argue that for maximal benefits during atherosclerosis regression, both isoforms of LXR are needed in BM-derived CD $68^{+}$cells.

\section{Results}

LXR pan-agonist treatment of Apoe- ${ }^{-1}$ mice increases CCR7 expression in plaque $\mathrm{CD} 68^{+}$cells and reduces plaque size. Concurrent with plaque regression, in laser-captured $\mathrm{CD} 68^{+}$cells there was upregulation of $N r 1 h 3$ (27) and Nr1h2 (data not shown) mRNAs. To begin to test the functional relationship between LXR isoforms and plaque regression, Apoe $e^{-/-}$mice were placed on Western diet for 16 weeks, after which they were injected intravenously with the pan-LXR agonist T0901317 at $50 \mathrm{mg} / \mathrm{kg} / \mathrm{d}$ (or an equivalent volume of saline) for 2 weeks. As expected (38), LXR agonist treatment did not improve the plasma lipoprotein profile; in fact, consistent with previous reports $(38,39)$, it caused an elevation of approximately 2 -fold $(P<0.05)$ in plasma triglycerides without statisti- 
A

B
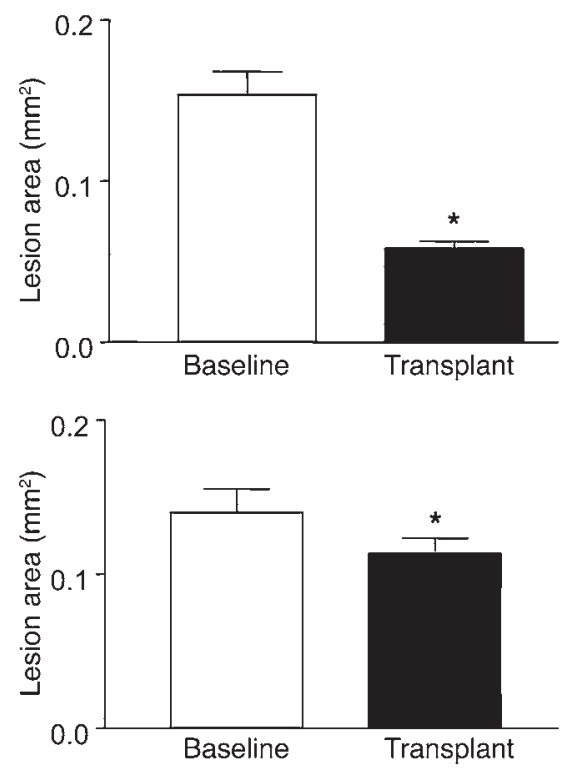

C

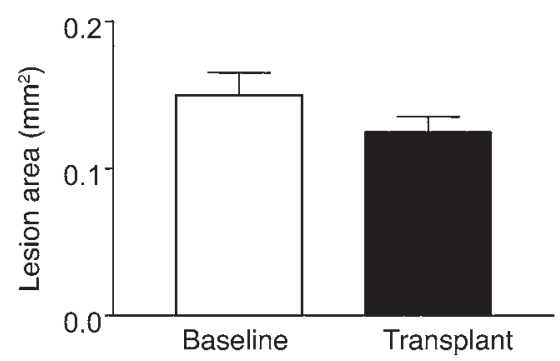

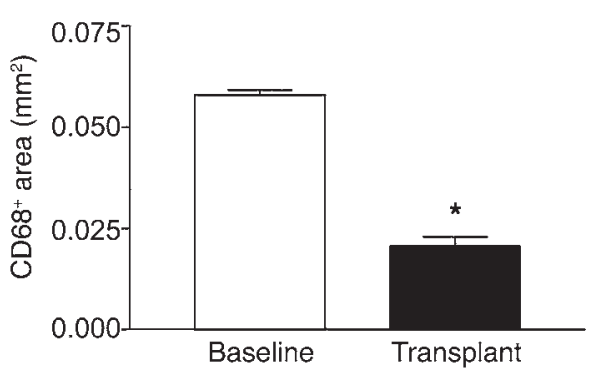
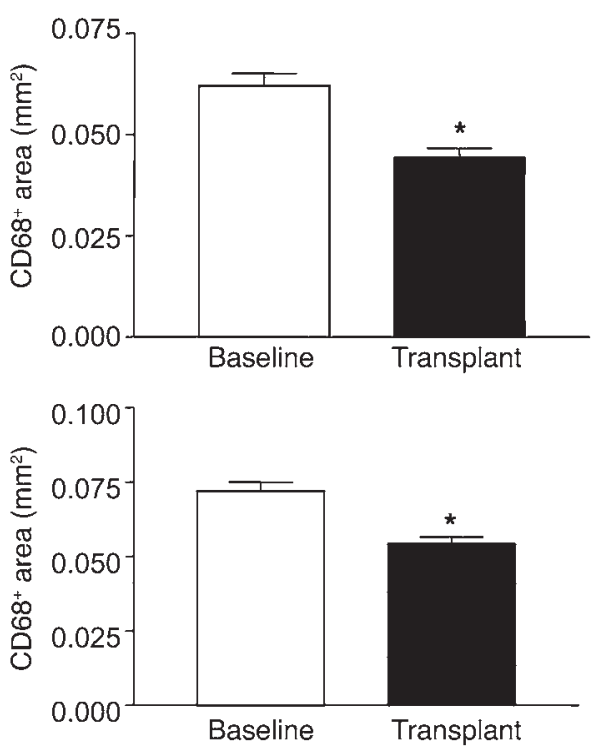

Figure 2

$\mathrm{LXR} \alpha$ and $\mathrm{LXR} \beta$ are required for maximal plaque regression. Aortic arch donors were $A p o e^{-/-}$mice transplanted with $\mathrm{BM}$ from $A p o e^{-/-}(\mathbf{A} ; n=10)$,

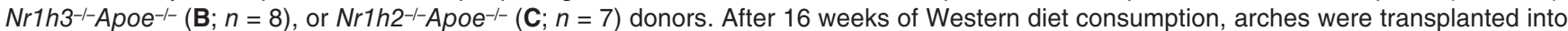
WT recipients, and the indicated morphometric analyses were performed. ${ }^{\star} P<0.05$ versus baseline. Note the similar lesion areas among the baseline mice in each group.

cally significant changes in total cholesterol or HDL-cholesterol levels (Figure 1A). After 2 weeks of treatment, there was modest regression of atherosclerotic lesions, in spite of continued Western diet consumption and hyperlipidemia, as assessed by plaque $\mathrm{CD} 68^{+}$cell content $(25 \%$ reduction, $P<0.05$; Figure $1 \mathrm{~B})$. This was not likely the result of changes in $C d 68$ expression by the LXR agonist, since there were no significant effects on Cd68 mRNA abundance in LXR agonist-treated mouse macrophages (data not shown). Importantly, in $\mathrm{Cr} 7^{-/-} \mathrm{Apoe}^{-/-}$double-knockout mice, we found no significant change in $\mathrm{CD}^{-} 8^{+}$cell content (Figure 1C), suggesting a requirement for CCR7 expression in LXR agoniststimulated regression.

To study specific gene expression changes in the plaque $\mathrm{CD} 68^{+}$ cells, they were laser captured, their mRNA was purified, and quantitative real-time RT-PCR (qRT-PCR) assays were performed. As shown in Figure 1D, known LXR target genes were upregulated, such as Abca1 (4.8-fold, $P<0.05$ ) and Abcg1 (3.6-fold, $P<0.05)$. In addition, $C c l 2$ (which encodes monocyte chemoattractant protein 1 ) was downregulated (data not shown), consistent with the ability of LXR to trans-repress NF- $\kappa \mathrm{B}$, a major regulator of $\mathrm{C} c \mathrm{l} 2$ expression $(36,40)$. Most notably, $C c r 7$ mRNA expression was upregulated approximately 3 -fold $(P<0.05$; Figure $1 D)$, which was confirmed at the protein level using immunohistochemistry (Figure 1, E and
F, and Supplemental Figure 1; supplemental material available online with this article; doi:10.1172/JCI38911DS1).

$L X R \alpha$ and $L X R \beta$ are both required for maximal atherosclerosis regression. Given the results with the LXR pan-agonist, we sought to determine the contribution of each LXR isoform to regression. This was approached by studying Apoe $e^{-/}$mice whose BM cells were made deficient in apoE, or in apoE and one of the LXR isoforms, by BM transplantation (see Methods). After BM reconstitution, mice were fed the Western diet for 16 weeks and used as aortic arch donors, with WT mice as the recipients. For all 3 groups, the lipoprotein profiles were essentially the same at this time point (data not shown). The baseline lesion areas were also similar (Figure 2, A-C), with an ANOVA test of differences among the means being nonsignificant.

At the 3-day post-transplantation time point (which we have previously used; refs. 25,27 ), reductions in plaque area and CD68 ${ }^{+}$ cell content were impaired in grafts from $\mathrm{Nr} 1 \mathrm{~h} 3^{-/-} \mathrm{Apoe}^{-/-}$and $\mathrm{Nr} 1 \mathrm{~h} 2^{-/-} \mathrm{Apoe}^{-/-}$mice (Figure 2, B and C). For example, there was a $65 \%$ reduction in $\mathrm{CD} 8^{+}$cell content when $\mathrm{Apoe}^{-/-}$mice $\left(\mathrm{Nr}_{1} \mathrm{~h} 3^{+}\right.$ and $\mathrm{Nr} 1 \mathrm{~h} 2^{+}$) were used as donors, but only a $35 \%$ or $28 \%$ reduction from $\mathrm{Nr} 1 \mathrm{~h} 3^{-/-} \mathrm{Apoe}^{-/-}$or $\mathrm{Nr} 1 \mathrm{~h} 2^{-/-} \mathrm{Apoe}^{-/-}$donors, respectively (both $P<0.01$ versus $\left.A p o e^{-/-}\right)$. Consistent with this pattern of results was the statistical analysis of the absolute areas of the lesions and of $\mathrm{CD} 68^{+}$immunostaining, which showed that each parameter was 


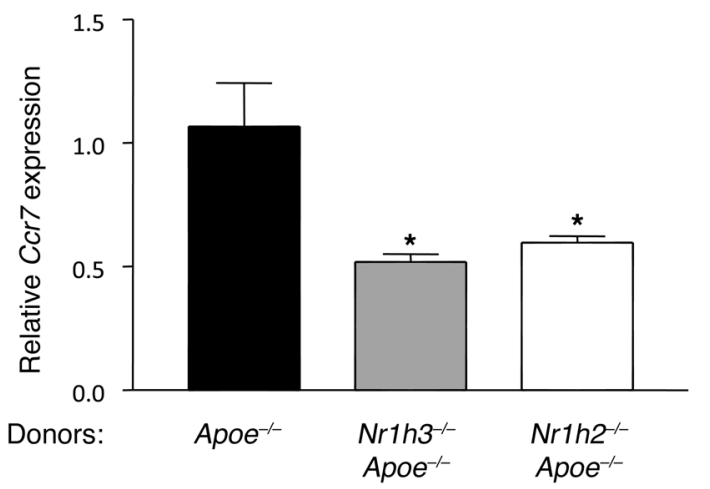

Figure 3

Both $\mathrm{LXR}$ isoforms are required in $\mathrm{CD}^{+} 8^{+}$cells in vivo for the maximal induction of $\mathrm{C} c r 7$ gene expression. Aortic arches from $\mathrm{Apoe}^{-/-}$mice reconstituted with BM from $\mathrm{Apoe}^{--}, \mathrm{Nr}_{\mathrm{h}} \mathrm{h}^{--} \mathrm{Apoe}^{-/}$, or $\mathrm{Nr} 1 \mathrm{~h} 2^{--} \mathrm{Apoe}^{-/-}$ donors were transplanted into WT recipients. $C D 68^{+}$cells were laser captured from the plaques of the indicated donors, and Ccr7 mRNA levels were measured in the isolated RNA by qRT-PCR and normalized to Ppia mRNA. * $P<0.05$ versus $A p o e^{-1-}$.

more significantly reduced in the WT recipients when the donors were Apoe $e^{-/-}$mice expressing both LXRs (Supplemental Table 1). Although deficiency of either LXR isoform impaired reductions in the absolute values of lesion area and of $\mathrm{CD}^{2} 8^{+}$cell content, consistent with the percentage changes noted above, the severity tended to be slightly greater for deficiency of LXR $\beta$. That the results based on immunostaining reflected true changes in the cell population, and not downregulation of $C d 68$ expression by LXR deficiency, was supported by the finding of a high correlation $(r=0.96)$ between immunostaining results using antibodies for CD68 and another standard macrophage marker, MOMA-2 (Supplemental Figure 1).

Given the association between the induction in plaque $\mathrm{CD} 68^{+}$ cells of genes encoding LXR isoforms and CCR7 in vivo during regression (27), we speculated that there might be reduced $\mathrm{Cor} 7$ expression resulting from LXR deficiency. As shown in Figure 3, this was indeed the case for each isoform. Because CCR7 function is required for regression in WT recipients (27), the results suggested that the blunted induction of $\mathrm{Ccr} 7$ gene expression with LXR isoform deficiency limited $\mathrm{CD} 68^{+}$cell emigration and consequently impaired regression. To directly test this possibility, we used a fluorescent bead approach previously established to quantify plaque monocyte-derived cell trafficking $(41,42)$. Briefly, circulating CCR2 $2^{\text {hi }}$ monocytes of the donor mice were labeled in vivo with the beads (see Methods and refs. 41 and 42). A fraction of the circulating bead-containing CCR2 ${ }^{\text {hi }}$ monocytes then enters the plaque (41). Because the beads are not biodegradable, any subsequent loss of beads from plaques must be due to carriage of the beads from the plaque, thereby providing a means to quantify egress (reviewed in ref. 43). After transplantation of the aortic arches, evidence for cell emigration is reflected in the number of beads remaining in the plaques. When this method is applied in the transplant model, the number of bead-positive cells appearing in the iliac and hepatic LNs can also be assessed as a measure of egress, since these 2 sites we previously established as destinations of the emigrating $\mathrm{CD}^{+} 8^{+}$cells $(25,27)$.

First, in the pre-transplant plaques, the content of labeled cells was comparable among the 3 groups (Figure 4A). This suggested that neither of the LXR isoforms regulated recruitment of CCR2 $2^{\text {hi }}$ monocytes into atherosclerotic plaques. At 3 days after transplant, we harvested the plaques as well as the iliac, hepatic, and brachial LNs. In the WT recipient mice, when the donors were Apoe ${ }^{-/-}$mice, bead frequency per plaque section was reduced $57 \%$ compared with the initial pre-transplant baseline $(P<0.05$; Figure $4 \mathrm{~B})$. Thus, approximately half of the beads were transported out of plaques over the 3 days in mice expressing both LXR isoforms; however, this migratory transport was significantly abrogated in the absence of either LXR $\alpha$ or LXR $\beta$ (Figure 4B). In general agreement, there were fewer beads found in the iliac and hepatic LNs in the mice that received aortic arches from the isoform-deficient mice (Figure 4, $\mathrm{C}$ and $\mathrm{D})$. The number of beads recovered from LNs, however, was a fraction (less than $10 \%$ ) of the number that emigrated from

\section{Figure 4}

Both LXR isoforms are required for maximal monocyte-derived cell emigration from plaques. 1 week prior to transplantation, circulating monocytes in $\mathrm{Apoe}^{-/-}, \mathrm{Nr}_{\mathrm{h}} 3^{-/-} \mathrm{Apoe}^{-/-}$, and $N r 1 h 2^{-l-}$ Apoe $^{-/-}$donor mice $(n=8$ per group) were labeled with fluorescent beads as described in Methods. Pretransplant $(\mathbf{A})$ and 3 days after transplant, aortic arches (B) as well as iliac (C), hepatic (D), and brachial (not shown) LNs were harvested, and the contents of beads in the plaques and nodes were determined (see Methods). There were no beads recovered from the brachial nodes in any group. Note that there were no statistically significant differences in baseline bead number among the 3 donor groups (A). ${ }^{*} P<0.05$ versus $A p o e^{-1}$.
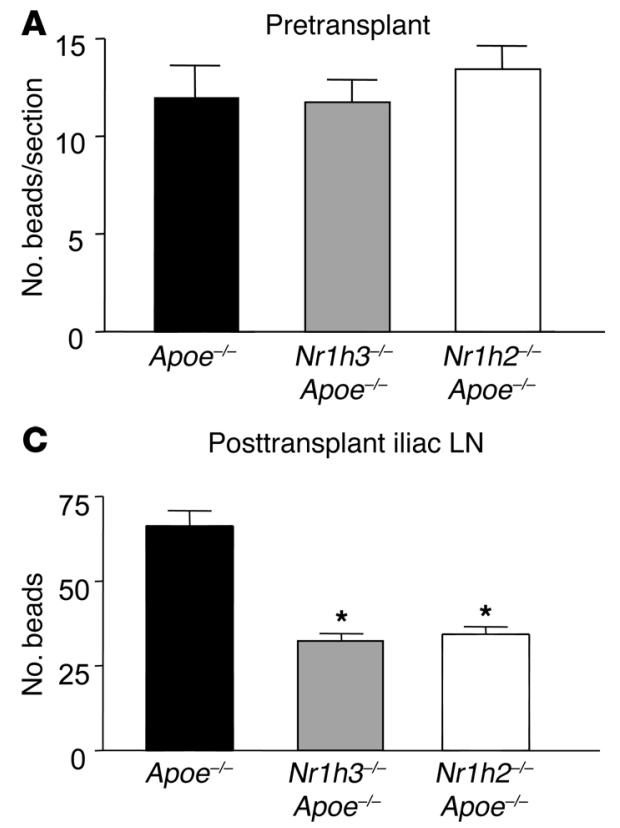
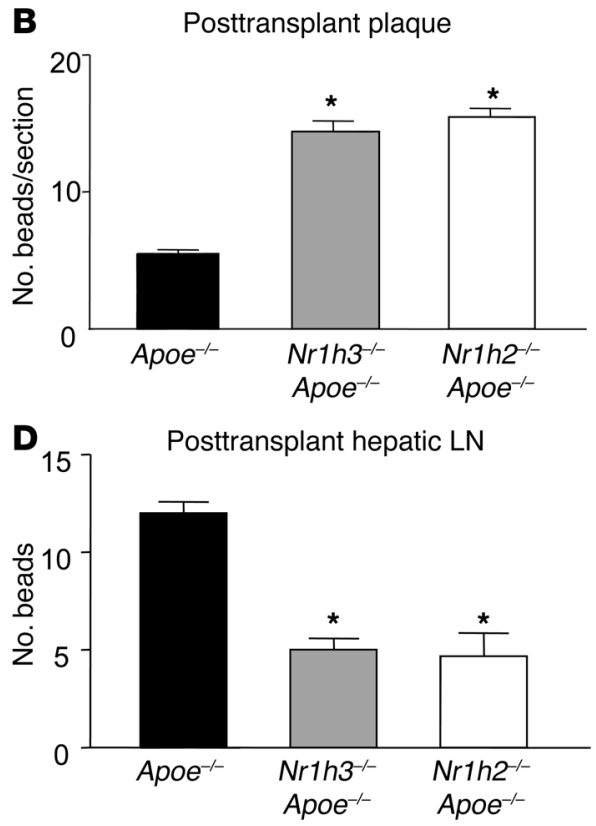
A

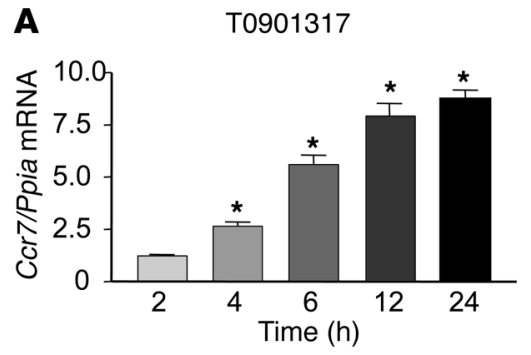

D

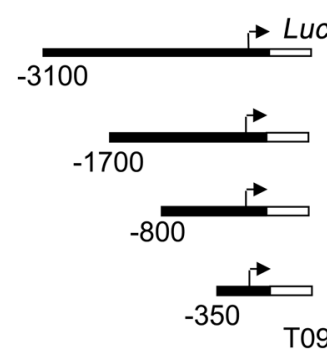

$\mathbf{F}$

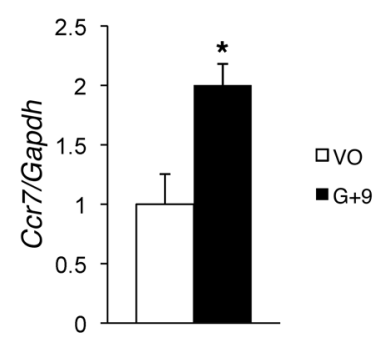

B $\quad$ T0901317 + actinomycin D

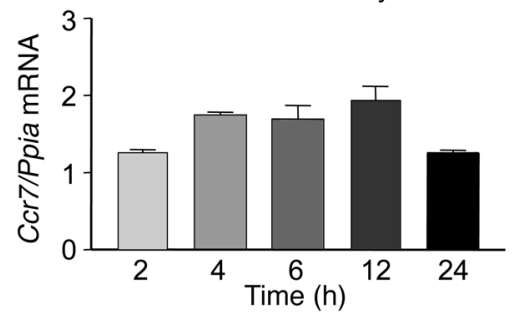

C

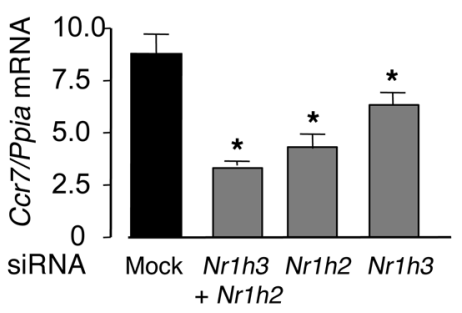

E
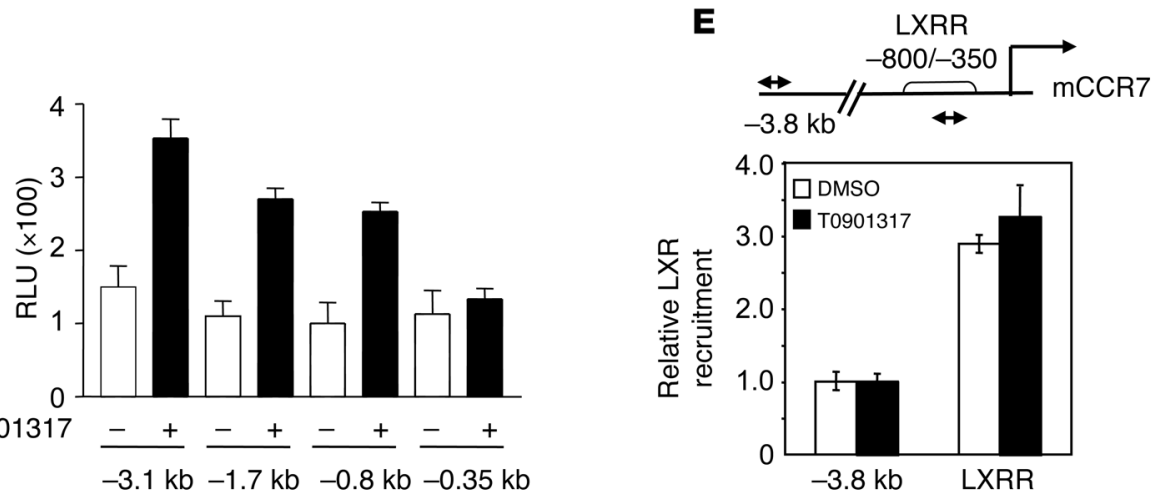

H
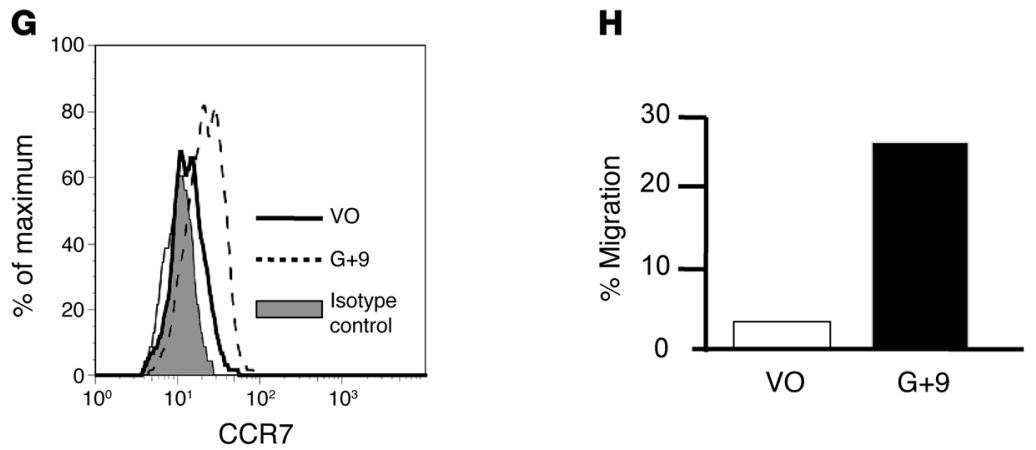

\section{Figure 5}

Regulation of Ccr7 expression and function by LXR agonists. (A-C) DC2.4 cells were (A) treated with $1 \mu \mathrm{M}$ T0901317 for the indicated times, (B) preincubated with actinomycin D, or (C) transfected with control siRNA (mock) or with siRNA specific for Nr1h3, Nr1h2, or both, then treated with T0901317. $y$ axes denote fold change of Ccr7 mRNA relative to Ppia. ${ }^{\star} P<0.05$ versus respective 2-hour or mock control. (D) CCR7 promoter luciferase reporter constructs (left). HEK293T cells transfected with the indicated constructs and with Nr1h3 and Nr1h2 expression plasmids were incubated with DMSO (-) or $1 \mu \mathrm{M}$ T0901317 for 24 hours. Shown is mean \pm SD luciferase activity normalized to $\beta$-galactosidase (relative luciferase activity; RLU). (E) DC2.4 cells were incubated with vehicle or $5 \mu \mathrm{M}$ T0901317 for 2 hours, and chromatin was prepared. Precipitated DNA was amplified using CCR7 primers located between -800 to -350 bp upstream of transcription start (LXR-responsive region; LXRR) and -3.8 kb (arrows), normalized to input chromatin. Results denote induction relative to vehicle-treated samples (set as 1). Shown is mean \pm SD for a representative experiment assayed in triplicate. (F) Primary immature human DCs were incubated overnight with DMSO (vehicle only; VO) or $5 \mu M$ GW3965 and $1 \mu \mathrm{M}$ 9-cis-retinoic acid $(G+9)$. $y$ axis denotes fold change of $C c r 7$ mRNA relative to Gapdh as mean \pm SD $(n=6) .{ }^{*} P=0.001$. (G) Primary immature human DCs were treated as in F and stained for CCR7 or with isotype-matched control antibody and analyzed by FACS. Representative results from 3 experiments are shown. $(\mathbf{H})$ Primary immature human DCs were treated as in $\mathbf{F}$, then placed in the top chamber of Transwell plates containing CCL21 in the bottom. 3 hours later, cells that migrated toward the lower chamber were counted and subtracted from cells that migrated in the absence of CCL21. Assays were performed in triplicate; shown is a representative experiment.

plaques. This difference may be technical, due to the particular time point chosen or to large losses of cells in the processing of the LN itself, but may also signify that other anatomical destinations are favored by plaque-emigrating cells rather than LNs.

Taken together, the morphometric, gene expression, and emigration data make a consistent, compelling case that both isoforms of LXR are required for maximal regression, and that their effects are mediated by their modulation of CCR7-dependent emigration of $\mathrm{CD}^{+} 8^{+}$cells from plaques.
Transcriptional regulation of CCR 7 by LXR isoforms. The studies in vivo strengthened our previous speculation (27) that an important component of the regression process in the transplant model is a positive relationship between induction of genes encoding LXRs and level of $\mathrm{Ccr} 7 \mathrm{mRNA}$ in plaque $\mathrm{CD}^{+} 8^{+}$cells. To begin to determine whether this relationship represents $\mathrm{C} c r 7$ transcription regulated by genes encoding LXRs, we examined the effect of LXR agonists on $\mathrm{C} c r 7$ mRNA abundance in the mouse immature DC line DC2.4 (44). Both synthetic and natural LXR agonists - 
T0901317 and 24(S),25 epoxycholesterol, respectively - increased the expression of $\mathrm{Ccr} 7 \mathrm{mRNA}$ in a time-dependent manner (Figure 5A and Supplemental Figure 2). The kinetic analysis revealed $\mathrm{C} c r 7$ mRNA was induced after 2 hours of ligand treatment and continued to increase throughout the 24-hour time course. This induction was virtually abolished by preincubation with actinomycin D, an inhibitor of RNA polymerase II-mediated transcription (Figure 5B and Supplemental Figure 2). Furthermore, the increase in mRNA was accompanied by more CCR7 protein and enhanced CCR7-mediated chemotaxis (Supplemental Figure 3, A and B). These results suggest that in DC2.4 cells, activation of LXR promotes the transcription of the $\mathrm{Ccr} 7$ gene and the production of functional protein.

Since the ligands used are neither LXR $\alpha$ nor LXR $\beta$ specific, we examined the contribution of $\operatorname{LXR} \alpha$ or $\operatorname{LXR} \beta$ to $C c r 7$ transcription in DC2.4 cells by reducing the LXR isoforms individually or in combination by RNA interference (siRNA). Recall that our results from the transplant studies indicate that in the absence of either LXR isoform, induction of Ccr7 mRNA in vivo was impaired in plaque $\mathrm{CD}^{+}{ }^{+}$cells. DC2.4 cells were transfected with siRNAs targeted to $N r 1 b 3$ or $N r 1 b 2$, or with a control siRNA, and the effect on $\mathrm{Ccr} 7$ gene expression was monitored after LXR agonist treatment. As shown in Supplemental Figure 4, A and B, the mRNA level of each isoform was reduced specifically by approximately $75 \%$ $(P<0.05)$. As expected, each LXR isoform compensated for the other in terms of supporting agonist-induced $A b c a 1$ expression (45), and the simultaneous reduction of both $N r 1 b 3$ and $N r 1 b 2$ mRNA markedly decreased this induction (Supplemental Figure 4C). As shown in Figure 5C, reducing Nr1b2 mRNA decreased the ligand-dependent induction of $\mathrm{Cr} 7 \mathrm{mRNA}$ to only 3-fold, compared with 9-fold for the control siRNA $(P<0.05)$. Reducing $N r 1 b 3$ mRNA also impaired this induction, but to a lesser degree (to approximately 6-fold, $P<0.05$ ). When siRNAs to both Nr1b3 and $N r 1 b 2$ were used, induction of $C c r 7$ mRNA was maximally reduced to approximately 2.5 -fold $(P<0.05)$. Furthermore, while knockdown of either isoform reduced the chemotaxis of the DC2.4 cells to CCR7-specific ligands, knockdown of both isoforms essentially eliminated this migration (Supplemental Figure 3, C-F).

To extend these results, we created reporter plasmids in which different lengths of the $5^{\prime}$ region of the mouse $\mathrm{Ccr} 7$ gene were fused to luciferase and then transfected into HEK293 cells, which express low levels of LXRs. As shown in Figure 5D, Ccr7 promoter activity was induced by the LXR agonist when both LXR $\alpha$ and LXR $\beta$ cDNAs were transfected with the 3.1-, 1.7-, or 0.8-kb reporter plasmid. Furthermore, this induction was lost when the promoter was shortened from 0.8 to $0.35 \mathrm{~kb}$, suggestive of an important cisacting element in the deleted segment. Preliminary studies indicated that this element is between -0.59 and $-0.41 \mathrm{~kb}(\mathrm{~N}$. Bloch, C. Wu, and M. Garabedian, unpublished observations).

In ChIP assays of DC2.4 cells, compared with a non-LXR-responsive region, there was a significant increase in the occupancy of LXR at the same regulatory region (Figure 5E), which, when deleted, impaired activation in the $\mathrm{Cr} 7$ promoter assays (Figure 5D). As a positive control, the occupancy of LXR at the promoter of $A b c a 1$, a known downstream target of LXR, was similar to that of $\mathrm{Ccr} 7$ (Supplemental Figure 5).

We also examined LXR agonist-dependent $\mathrm{Ccr} 7$ induction in primary human immature DCs. We found a significant (about 2-fold, $P=0.001$ ) increase of $C c r 7$ mRNA expression upon LXR ligand treatment, a concomitant upregulation of CCR7 protein on the cell surface by FACS, and a 5-fold stimulation of CCR7dependent chemotaxis toward its cognate ligand CCL21 (Figure 5, $\mathrm{F}-\mathrm{H})$. Together, the data in Figure 5 are consistent with CCR7 being regulated by LXR and suggest that both LXR isoforms contribute to the expression of $\mathrm{C} c r 7$ in vitro, as observed in vivo.

\section{Discussion}

We have previously reported that $C c r 7$ mRNA and protein were induced in plaque $\mathrm{CD}^{+} 8^{+}$cells and that inhibition of CCR7 ligands impeded regression and loss of $\mathrm{CD}^{+} 8^{+}$cells from plaque when the hyperlipidemic environment of the Apoe $e^{-/}$mouse was reversed by transplantation of their aortic arches into WT mice (27). Associated with CCR7 induction was an increase in Nr1b3 and Nr1b2 gene expression. This led us to hypothesize that the LXRs and CCR7 are functionally linked in regression. The results of the present study argue strongly that this is indeed the case, as reflected by multiple independent lines of evidence: (a) Treatment of Apoe $e^{-/-}$mice with an LXR agonist for 2 weeks induced $C c r 7$ gene expression in plaque $\mathrm{CD}^{+} 8^{+}$cells and led to their depletion in a CCR7-dependent manner. (b) Absence of Nr1b3 or Nr1b2 expression in BM-derived cells impaired the ability of $\mathrm{CD}^{+} 8^{+}$cells to maximally emigrate from Apoe ${ }^{-/}$plaques. (c) Both LXR $\alpha$ and LXR $\beta$ were required for maximal Ccr7 expression in vitro and in vivo in plaque $\mathrm{CD}^{6} 8^{+}$cells. (d) Treatment in vitro with LXR agonists increased $\mathrm{Ccr} 7$ gene expression and function in a mouse immature DC line as well as in primary human immature DCs.

There is a large and expanding body of literature on LXR $\alpha$ and LXR $\beta$ (reviewed, for example, in refs. 36,37 ), which has shown that they regulate a number of genes that coordinate lipogenic and RCT pathways. Recently, it has also been shown that LXRs also negatively regulate the inflammatory state of macrophages through effects on toll-like receptors and NF-кB (46, 47). Activation of LXRs and absence of LXRs have been shown to promote regression $(38,48)$ and exacerbate progression $(39,49)$, respectively, of atherosclerosis in mouse models. These effects of LXRs have been attributed to the aforementioned roles in RCT and inflammation. The present results propose an additional mechanism for LXR-atheroprotection, namely, their stimulation of $\mathrm{CD} 68^{+}$cell emigration from plaques through the induction of Ccr7. LXR-dependent acquisition of CCR7 function in $\mathrm{CD}^{+} 8^{+}$plaque cells is also consistent with previous work by us (50) and others $(24,48)$, as well as with the more general finding that the acquisition of migratory ability during differentiation of monocytes to DCs is concomitant with both LXR isoforms being expressed $(51,52)$.

As described in Results, the emigration of $\mathrm{CD} 68^{+}$cells from the plaques was assessed using a previously established bead-labeling technique $(42,53)$, which we used in a way that we believe to be novel, allowing for study of egress from, rather than entry into, plaques (43). An underlying, but reasonable, assumption is that the bead-labeled cells being tracked, including the CCR $2^{\text {hi }}$ subset of circulating monocytes initially labeled and any phagocytes to which they may transfer the beads within plaques, are representative of the behavior of all or most plaque phagocytes. Implicit in this approach is that the mechanism by which the cells emigrate may be CCR7 dependent or independent. Thus, it is possible that non-CCR7 migratory processes are regulated by LXR. In particular, the migration of labeled cells from plaques to the hepatic $\mathrm{LN}$, which likely requires passage through blood rather than traditional lymphatic routes (25), may occur by mechanisms both 
CCR7 independent and dependent. That fewer cells emigrated from plaques to the hepatic LN in the absence of either LXR $\alpha$ or LXR $\beta$ would be consistent with non-CCR7 migratory pathways being regulated by LXRs; however, based on the results in the $\mathrm{Cr} 7^{-1-}$ Apoe $^{-/-}$mice (Figure $1 \mathrm{C}$ ), such mechanisms may make a quantitatively small contribution.

The results from LXR agonist treatment of $\mathrm{Crr}^{-/-} \mathrm{Apoe^{-/- }}$ mice support a functional relationship between LXR and CCR7 in regression in vivo, and the results in vitro, in which we manipulated the level of Nr1b3- or Nr1b2-specific mRNA, showed that full induction of $\mathrm{Ccr} 7$ by the pan-agonist required both isoforms. While these results suggest that CCR7 function and gene expression are regulated by LXRs, whether $\mathrm{C} c r 7$ is a direct or indirect transcriptional target of them remains to be established. The regulatory region that confers LXR responsiveness in vitro does not contain a canonical LXR DR4 binding element, which suggests that a different type of cis-acting element is responsible for activation by LXR at $C$ cr7. In fact, the $C d 36$ gene has been shown to be a transcriptional target of LXR $\alpha$ through a non-DR4 response element (54). Additionally, there is a promoter proximal sterol response element, which could be indirectly regulated through LXR effects on RCT.

Although it has been recently suggested that $\operatorname{LXR} \alpha$ and $\operatorname{LXR} \beta$ have distinct roles in atherosclerosis progression (39), the prevailing view is that the LXR isoforms are functionally redundant because they regulate the expression of a number of shared target genes. By this logic, any differential effects of isoform deficiency would be due mainly to the relative abundance of the isoforms in tissues (55-61). For example, liver expresses predominately LXR $\alpha$ (62), so hepatic LXR $\beta$ deficiency would be expected to have little effect. In contrast, macrophages express both isoforms at similar levels, consistent with our finding that deficiency of either LXR isoform impaired the induction of $\mathrm{Cor} 7$ and the depletion of plaque $\mathrm{CD} 68^{+}$cells. This would suggest that one explanation for the requirement of both LXR isoforms for maximal regression is that the total level of available LXR in plaque $\mathrm{CD}^{2} 8^{+}$cells is a limiting factor in $\mathrm{C} c r 7$ expression, as has been shown for other genes in macrophages (63). Consistent with this idea, Nr1b3 mRNA (27) and LXR $\alpha$ protein (Supplemental Figure 6) increased significantly in macrophages in the regression versus the progression environment. It should be noted that in humans, LXR $\alpha$ is autoinducible (64), so the possibility remains that in a regressing plaque, sufficient LXR activity may be achieved independent of LXR $\beta$ abundance, especially in the context of the substantial levels of endogenous ligands in foam cells.

The question of whether LXR $\alpha$ and LXR $\beta$ are both needed for maximal atheroprotection becomes particularly important when considering a current therapeutic strategy focused on the development of LXR $\beta$-selective ligands, which would spare the increase in lipogenesis in the liver from stimulation of $\operatorname{LXR} \alpha(45,65)$. The present studies suggest that the selective approach may be suboptimal, as also suggested by studies in another pathological process, Alzheimer disease, in which deficiency in either isoform was associated with increased amyloid deposition (66), and in LXR $\alpha$ deficient mice, in which full induction of various target genes in macrophages was limited upon agonist treatment (63).

It will be interesting in the future to define phenotypic changes besides the acquisition of migratory activity in the plaque $\mathrm{CD} 68^{+}$ cells in the different environments (i.e., baseline, progression, and regression) and how LXR isoform deficiency affects these changes. That there are likely to be many changes is indicated by preliminary microarray analysis of gene expression in $\mathrm{CD}^{+} 8^{+}$cells laser-captured from plaques contained in aortic segments transplanted from Apoe $e^{-/-}$donors to Apoe $e^{-/-}$or WT recipients (J.E. Feig, O. Puig, V. Reiser, M.J. Garabedian, and E.A. Fisher, unpublished observations). Approximately 700 statistically significant differences were found between the progression (Apoe $\left.e^{-/}\right)$and regression (WT) recipient environments. It is important to consider these results in light of the current controversy over whether completely separate subpopulations of monocyte-derived cells exist $(28,67)$. If so, they could still be so numerous that no one marker, or even combinations of markers, will accurately categorize any particular subset. Even for factors and markers commonly accepted by many investigators to relate to a particular type of monocyte-derived cell, their application to the phenotyping of plaque $\mathrm{CD}^{2} 8^{+}$cells in the different atherosclerotic environments may be challenging, given our own findings that treatment of BM-derived macrophages with IL-4 (an inducer of the M2 macrophage phenotype) stimulates expression of CD11c, usually considered to be a marker of mouse DCs, and that treatment with LPS (an inducer of the M1 phenotype) stimulates expression of arginase I, usually considered to be a marker of M2 macrophages (M. Sanson, E.L. Gautier, G. Randolph, and E.A. Fisher, unpublished observations). Perhaps the most conservative view of our present and past studies, then, is that the change in the plaque's environment from progression to regression causes major phenotypic changes in the monocyte-derived cell population that do not correspond to a well-defined category.

It is also interesting to note that the induction of $\mathrm{Ccr} 7$ by LXR agonists in vitro in the DC2.4 cells is also observed in primary human immature DC, but in mature human DCs, which express high constitutive levels of $\mathrm{C} c r 7 \mathrm{mRNA}$ and protein, LXR ligand treatment suppressed Ccr7 expression (data not shown). This is consistent with a recent study demonstrating LXR ligands produced by tumor cells inhibit Cor7 expression on mature DCs (68). These observations most likely reflect the requirement of specific features of the phenotypic state of monocyte-derived cells for $\mathrm{Ccr} 7$ responsiveness to LXR. Consistent with this idea are recent studies that suggest that polarization of macrophages to the M2 lineage by IL-4 facilitates $C c r 7$ activation by LXR agonists (I. Pineda-Torra, M. Sanson, M.J. Garabedian, and E.A. Fisher, unpublished observations). Moreover, $\mathrm{CD}^{+} 8^{+}$plaque cells under the regression environment exhibit a number of substantial changes compared with those under progression (aforementioned unpublished observations from microarray studies and refs. 25-27). Clearly, additional studies will be needed to elucidate the mechanisms underlying the relationship between LXR-dependent induction of $\mathrm{Ccr} 7$ expression and monocyte-derived phenotypic features.

In conclusion, after the reduction of hyperlipidemia, maximal regression of atherosclerotic lesions is supported by the expression of both LXR isoforms. In addition, multiple lines of evidence establish LXRs as regulators of $\mathrm{Ccr} 7$ expression and function in vitro and in vivo. Furthermore, we have uncovered a mechanism - the stimulation of $\mathrm{CD} 68^{+}$cell emigration from plaques - as an atheroprotective effect of LXRs, which we believe to be novel. The results for the different LXR isoforms suggest that although a selective LXR $\beta$ agonist may avoid undesirable hypertriglyceridemia, it may not maximally promote plaque regression. With progress in tissue-specific drug targeting (69-72), one potential alternative approach to halting the progression of atherosclerosis and promoting its regression would be to develop macrophagespecific LXR agonists. 


\section{Methods}

\section{Cell culture}

An immature DC line, DC2.4 (44), was provided by T. Moran (Mount Sinai School of Medicine, New York, New York, USA) and maintained at $37^{\circ} \mathrm{C}(5 \%$ $\mathrm{CO}_{2}, 95 \%$ air) in culture medium consisting of DMEM (Invitrogen) supplemented with $10 \%$ FBS (Invitrogen). For ligand treatments, cells were cultured in DMEM supplemented with $1 \%$ FBS (low serum) and $1 \mu \mathrm{M}$ of the synthetic LXR agonist T0901317 (Cayman Chemicals) or $10 \mu \mathrm{M} 24(\mathrm{~S}), 25$ epoxycholesterol (Sigma-Aldrich). Actinomycin (Sigma-Aldrich) was used at $0.5 \mu \mathrm{g} / \mathrm{ml}$ for 12 hours prior to LXR agonist treatment in order to assess whether the LXR effect on CCR7 expression was at the transcriptional level.

\section{siRNA}

DC2.4 cells were plated at a concentration of $2 \times 10^{5}$ cells/well in 6-well plates. The next day, cells were transfected using $\operatorname{LXR} \alpha, \operatorname{LXR} \beta$, or both in siRNA SMART pools (Dharmacon) at a final concentration of 50-100 nM in combination with the transfection reagent, following the manufacturer's protocol. As a control, cells were transfected with nonspecific siRNA (Dharmacon). After 24 hours of transfection, the media were changed; after another 24 hours, RNA was isolated.

\section{Animals and aortic transplantation}

All procedures were approved by the Animal Care and Use Committee at New York University School of Medicine. The transplantation model has been previously described $(22,23)$. In the present studies, WT recipients were always matched with the donors for strain (C57BL/6), age (20 weeks), and sex (male). A group of donors from each genotype was sacrificed for baseline lesion analysis. To test the effects of a LXR agonist on $\mathrm{CD}^{2} 8^{+}$cell content, lesion size, and $\mathrm{CD}_{68}{ }^{+}$cell gene expression in vivo, $\mathrm{Apoe}^{-/}$mice were weaned at 1 month onto a $21 \%$ (wt/wt) fat, $0.15 \%$ cholesterol Western diet (Research Diets), until 20 weeks of age. At that time, half were fed Western diet in addition to receiving daily intravenous injections of T0901317 $(50 \mathrm{mg} / \mathrm{kg} / \mathrm{d})$ for 2 weeks, and the other half continued on Western diet and were given daily injections of saline. Although it is typically given in the diet or by gavage, we prepared $\mathrm{T} 0901317$ for injection by mixing it with saline and vortexing vigorously because of its relative aqueous insolubility. $\mathrm{C} c 7^{-1-}$ mice (obtained from S. Lira, Mount Sinai School of Medicine, with permission from M. Lipp, who developed these mice; ref. 31) were crossed with $A p o e^{-/-}$mice to ultimately generate $\mathrm{Crr}^{-1-} \mathrm{Apoe}^{-/-}$double-knockout mice. LXR agonist treatment of these mice was performed using the protocol described above.

BM transplantations from Apoe $e^{-/}, \mathrm{Nr}_{\mathrm{H}} \mathrm{h3}^{-/-} \mathrm{Apoe}^{-/}$, or $\mathrm{Nr} 1 \mathrm{h2^{-/- }} \mathrm{Apoe}^{-/-}$ donors into $A \mathrm{poe}^{-/-}$recipients was performed in the UCLA Howard Hughes Medical Institute Department of Pathology and Laboratory Medicine lab to generate mice with BM-derived, monocyte-derived cells deficient in apoE or in apoE and one of the isoforms of LXR. They were placed on Western diet for 16 weeks, after which they were ready to serve as aortic arch donors.

\section{Lesion assessment by histology and morphometry}

The pretransplant and grafted arches were removed, embedded in OCT, and frozen. Serial sections ( $6 \mu \mathrm{m}$ thick) were obtained using a cryostat. To detect the plaque cells of interest, sections were stained for CD68 (rat anti-mouse, $2 \mu \mathrm{g} / \mathrm{ml}$; Serotec). Briefly, fixed sections were stained for 1 hour at room temperature with the primary antibody, followed by incubation with biotinylated goat anti-rabbit Ig for 1 hour, reaction with streptavidin-linked alkaline phosphatase, color development with substrate, and hematoxylin counterstaining. Negative controls were performed with an irrelevant primary antibody. CCR7 was detected by a similar approach, except that a chimeric protein was used, in which the $\mathrm{N}$-terminal end is the binding domain of the CCR7 ligand CCL19, and the C-terminal end is the human Fc Ig fragment. This reagent was provided by T. Springer (Harvard Medical School, Boston, Massachusetts, USA) and used as described previously (73); positive and negative controls to confirm its specificity are shown in Supplemental Figure 1. Morphometric measurements were performed on digitized images of CD68-stained serial sections of each arch using Image-Pro Plus software (Media Cybernetics). At least 5 sections per vessel were analyzed, and the mean was used as the summary value.

\section{Labeling and tracking of blood monocytes}

For selective labeling of Ly-6Chi (i.e., CCR2 $2^{+}$) monocytes (41, 42, 53), $250 \mu \mathrm{l}$ of liposomes containing clodronate were intravenously injected into Apoe $e^{-/-}$, $\mathrm{Nr}_{\mathrm{H}} \mathrm{b3}^{-/-} \mathrm{Apoe}^{-/-}$, or $\mathrm{Nr} 1 \mathrm{h2^{-/ }} \mathrm{Apoe}^{-/-}$donor mice, followed by $250 \mu \mathrm{l}$ of fluorescent microspheres injected 24 hours later. At 3 days after transplantation into the WT mice, iliac, hepatic, and brachial LNs were harvested along with the transplanted aortae. Briefly, each node was digested in a 1-ml solution of collagenase D (Sigma-Aldrich) for 3 hours at $37^{\circ} \mathrm{C}$, after which $40-\mu l$ aliquots were spotted onto glass slides. Fluorescent beads in each aliquot were manually counted under a Leica fluorescent microscope.

\section{Human monocyte-derived DCs}

Isolation and treatment with LXR agonists. Buffy coats, purchased from New York Blood Center, served as sources for PBMCs. Human monocyte-derived DCs were differentiated from monocyte fractions of PBMCs as described previously (74). Briefly, monocytes that attached to the tissue culture plates from buffy coats were grown at $37^{\circ} \mathrm{C}$ on $10-\mathrm{cm}^{2}$ plates in $10 \mathrm{ml}$ of culture media containing $300 \mathrm{IU} / \mathrm{ml}$ recombinant human IL-4 (Immunex) and $116 \mathrm{IU} / \mathrm{ml}$ recombinant human GM-CSF (R\&D). On days 2 and 4 of culture, additional IL-4 and GM-CSF was added. Immature DCs were harvested on day 5 for use in experiments. In preliminary experiments using T0901317 as the LXR agonist, we noted that its effects on CCR7 expression at the RNA and surface protein levels were augmented by the retinoid $\mathrm{X}$ receptor (RXR) ligand 9-cis retinoic acid (data not shown). Because T0901317 has agonist activity for farnesoid X receptor (FXR; ref. 75) and pregnane X receptor (PXR; ref. 76), to ensure that the effects we observed were caused by LXR-dependent mechanisms, we switched to the more specific agonist GW3965 and continued the supplementation with 9-cis retinoic acid. Thus, for the assays described below, primary immature DCs were first incubated overnight with DMSO vehicle only or with $5 \mu \mathrm{M}$ GW3965 and $1 \mu \mathrm{M}$ 9-cis retinoic acid. Ccr7 mRNA abundance after this these treatments was measured by qRT-PCR.

Surface staining. DCs were stained with CD14 and CD11c anti-human antibodies (BD) to ensure the quality of DCs generated. Upon maturation with the compounds of choice, the levels of CCR7 (BD) were monitored by surface staining on fluorescence-activated cell sorting.

Transwell DC migration assay. DCs $\left(1 \times 10^{5}\right)$ in $200 \mu \mathrm{l}$ media ( $1 \%$ plasma in RPMI) were placed in the upper chamber of a $5-\mu \mathrm{m}$ pore size 24 -well transwell plate (Costar). In the lower chamber, $500 \mu \mathrm{l}$ media was placed and supplemented with CCL21 at $200 \mathrm{ng} / \mathrm{ml}$. Transwell plate was placed in the incubator at $37^{\circ} \mathrm{C}$ for 4 hours. The cells in the lower chamber were then enumerated using either trypan blue (Cellgro) or CellQuanti-Blue (BioAssay Systems).

\section{Laser capture microdissection}

To isolate $\mathrm{CD} 8^{+}$cells from plaques, laser capture microdissection was performed with PixCell II (Arcturus Bioscience), as we reported previously (77). Briefly, 6- $\mu \mathrm{m}$ frozen sections were dehydrated in ethanol, placed twice in xylene, and air dried. At $100-\mu \mathrm{m}$ intervals, sections were immunostained for CD68 and used as guide slides for the next 5 serial sections. RNA was isolated by the Qiagen RNeasy MicroIsolation kit and treated with DNase. The concentration of RNA was determined by the Ribogreen RNA Quantitation kit (Invitrogen), and the RNA quality veri- 
fied with the Agilent 2100 Bioanalyzer. Each RNA sample from laser-captured foam cells represents a pool of 3 mice.

\section{qRT-PCR}

RNA abundance was determined by qRT-PCR using $100 \mathrm{pg}$ total RNA. The primer and probe sequences for Nr1b3 (encoding LXR $\alpha$ ), Nr1b2 (encoding LXR $\beta$ ), Cd68 (encoding CD68), Abca1 (encoding ABCA1), Abcg1 (encoding ABCG1), Ccl2 (encoding MCP-1), Ccr7 (encoding CCR7), and Ppia (encoding cyclophilin A) are the same as described previously (27, 77-79). All data were normalized to Ppia and expressed as fold change over controls. For the laser-captured cell data, the results are from 2 independent samples, each representing a pool of $\mathrm{CD}^{+} 8^{+}$cell RNA from 3 animals. For the in vitro data, the results represent 2 replicate experiments with 3 wells per treatment.

\section{ChIP assays}

Assays were performed as described previously (80), with the following modifications. After treatments ( 2 hours), the cells were washed twice in PBS and first cross-linked for 20 minutes at room temperature with 1.6 mM DSP (Pierce) before formaldehyde cross-linking. The sonication and immunoprecipitation buffer consisted of $10 \mathrm{mM}$ Tris, $1 \mathrm{mM}$ EDTA, $140 \mathrm{mM} \mathrm{NaCl}, 5 \%$ glycerol, $1 \%$ Triton X-100, and $1 \times$ freshly added protease inhibitor cocktail (Sigma-Aldrich). Washes were performed as described in the Upstate ChIP protocol, except that the buffers did not contain any SDS detergent. DNA ( $2 \mu \mathrm{l})$ was amplified by real-time PCR using the Hot Start-IT SYBR green mix (USB).

\section{Lipid and lipoprotein analyses}

Blood samples were obtained from the retroorbital plexus of the various strains of mice studied. Plasma total cholesterol and triglyceride levels were determined by colorimetric enzymatic assays that were adapted to the 96-well plate format (Infinity Total Cholesterol Reagent or Infinity Triglyceride Reagent; Sigma-Aldrich). Plasma HDL-cholesterol was determined by precipitating non-HDL-cholesterol (Wako Diagnostic), then assaying the remaining supernatant by the Infinity Total Cholesterol Reagent.

\section{Statistics}

Data are expressed as mean \pm SEM and were analyzed by 2-tailed Student's $t$ test or by 1-way ANOVA with Bonferroni post-test as appropriate for multiple comparisons. A $P$ value less than 0.05 was considered significant.

\section{Acknowledgments}

This work was supported by NIH grant HL-084312 (to E.A. Fisher), NIH grant HL-066088 and the Howard Hughes Medical Institute (to P. Tontonoz), NIH fellowships AG-029748 (to J.E. Feig) and HL-098129 (to Y. Vengrenyuk), and by Philip Morris USA Inc. and Philip Morris International (to M.J. Garabedian). We thank Gwendalyn Randolph for editorial advice and both her and Julie Helft (both at Mount Sinai School of Medicine) for scientific and technical support on the fluorescent bead protocol.

Received for publication July 19, 2010, and accepted in revised form September 15, 2010.

Address correspondence to: Edward A. Fisher, Department of Medicine, Division of Cardiology, NYU School of Medicine, Smilow 8, 522 First Avenue, New York, New York 10016, USA. Phone: 212.263.6631; Fax: 212.263.6632; E-mail: edward.fisher@nyumc.org.
1. Gaziano TA. Cardiovascular disease in the developing world and its cost-effective management. Circulation. 2005;112(23):3547-3553.

2. Grundy SM. Cholesterol and coronary heart disease. A new era. JAMA. 1986;256(20):2849-2858.

3. Grundy SM, et al. Implications of recent clinical trials for the National Cholesterol Education Program Adult Treatment Panel III Guidelines. J Am Coll Cardiol. 2004;44(3):720-732.

4. Grundy SM, et al. A summary of implications of recent clinical trials for the National Cholesterol Education Program Adult Treatment Panel III guidelines. Arterioscler Thromb Vasc Biol. 2004;24(8):1329-1330.

5. Grundy SM, et al. Implications of recent clinical trials for the National Cholesterol Education Program Adult Treatment Panel III guidelines. Circulation. 2004;110(2):227-239.

6. McMahan CA, et al. PDAY risk score predicts advanced coronary artery atherosclerosis in middle-aged persons as well as youth. Atherosclerosis. 2007;190(2):370-377.

7. LaRosa JC, et al. Intensive lipid lowering with atorvastatin in patients with stable coronary disease. NEngl J Med. 2005;352(14):1425-1435.

8. Nissen SE. Effect of intensive lipid lowering on progression of coronary atherosclerosis: evidence for an early benefit from the Reversal of Atherosclerosis with Aggressive Lipid Lowering (REVERSAL) trial. Am J Cardiol. 2005;96(5A):61F-68F.

9. Nicholls SJ, et al. Effect of atorvastatin ( $80 \mathrm{mg} /$ day) versus pravastatin $(40 \mathrm{mg} /$ day) on arterial remodeling at coronary branch points (from the REVERSAL study). Am J Cardiol. 2005;96(12):1636-1639.

10. Nissen SE, et al. Effect of very high-intensity statin therapy on regression of coronary atherosclerosis: the ASTEROID trial. JAMA. 2006;295(13):1556-1565.

11. Collins R, Armitage J, Parish S, Sleigh P, Peto R. MRC/BHF Heart Protection Study of cholesterol- lowering with simvastatin in 5963 people with diabetes: a randomised placebo-controlled trial. Lancet. 2003;361(9374):2005-2016.

12. Zhang SH, Reddick RL, Piedrahita JA, Maeda N. Spontaneous hypercholesterolemia and arterial lesions in mice lacking apolipoprotein E. Science. 1992;258(5081):468-471.

13. Nakashima Y, Plump AS, Raines EW, Breslow JL, Ross R. ApoE-deficient mice develop lesions of all phases of atherosclerosis throughout the arterial tree. Arterioscler Thromb. 1994;14(1):133-140.

14. Ishibashi S, Brown MS, Goldstein JL, Gerard RD, Hammer RE, Herz J. Hypercholesterolemia in low density lipoprotein receptor knockout mice and its reversal by adenovirus-mediated gene delivery. J Clin Invest. 1993;92(2):883-893.

15. Breslow JL. Mouse models of atherosclerosis. Science. 1996;272(5262):685-688.

16. Williams KJ, Feig JE, Fisher EA. Cellular and molecular mechanisms for rapid regression of atherosclerosis: from bench top to potentially achievable clinical goal. Curr Opin Lipidol. 2007;18(4):443-450.

17. Desurmont $\mathrm{C}$, et al. Complete atherosclerosis regression after human ApoE gene transfer in ApoE-deficient/nude mice. Arterioscler Thromb Vasc Biol. 2000;20(2):435-442.

18. Harris JD, et al. Inhibition of atherosclerosis in apolipoprotein-E-deficient mice following muscle transduction with adeno-associated virus vectors encoding human apolipoprotein-E. Gene Ther. 2002;9(1):21-29.

19. Tsukamoto K, Tangirala R, Chun SH, Pure E, Rader DJ. Rapid regression of atherosclerosis induced by liver-directed gene transfer of ApoE in ApoE-deficient mice. Arterioscler Thromb Vasc Biol. 1999;19(9):2162-2170.

20. Raffai RL, Loeb SM, Weisgraber KH. Apolipoprotein E promotes the regression of atherosclerosis independently of lowering plasma cholesterol levels.
Arterioscler Thromb Vasc Biol. 2005;25(2):436-441.

21. Raffai RL, Weisgraber KH. Hypomorphic apolipoprotein E mice: a new model of conditional gene repair to examine apolipoprotein E-mediated metabolism. J Biol Chem. 2002;277(13):11064-11068.

22. Reis ED, et al. Dramatic remodeling of advanced atherosclerotic plaques of the apolipoprotein Edeficient mouse in a novel transplantation model. J Vasc Surg. 2001;34(3):541-547.

23. Chereshnev I, et al. Mouse model of heterotopic aortic arch transplantation. J Surg Res. 2003; 111(2):171-176.

24. Waldo SW, et al. Heterogeneity of human macrophages in culture and in atherosclerotic plaques. Am J Pathol. 2008;172(4):1112-1126.

25. Llodra J, Angeli V, Liu J, Trogan E, Fisher EA, Randolph GJ. Emigration of monocyte-derived cells from atherosclerotic lesions characterizes regressive, but not progressive, plaques. Proc Natl Acad Sci US A. 2004;101(32):11779-11784.

26. Trogan E, et al. Serial studies of mouse atherosclerosis by in vivo magnetic resonance imaging detect lesion regression after correction of dyslipidemia. Arterioscler Thromb Vasc Biol. 2004;24(9):1714-1719.

27. Trogan E, et al. Gene expression changes in foam cells and the role of chemokine receptor CCR7 during atherosclerosis regression in ApoE-deficient mice. Proc Natl Acad Sci U S A. 2006;103(10):3781-3786.

28. Geissmann F, Gordon S, Hume DA, Mowat AM, Randolph GJ. Unravelling mononuclear phagocyte heterogeneity. Nat Rev Immunol. 2010;10(6):453-460.

29. Qu C, et al. Role of CCR8 and other chemokine pathways in the migration of monocytederived dendritic cells to lymph nodes. J Exp Med. 2004;200(10):1231-1241.

30. Randolph GJ, Inaba K, Robbiani DF, Steinman RM, Muller WA. Differentiation of phagocytic monocytes into lymph node dendritic cells in vivo. Immunity. 1999;11(6):753-761. 
31. Forster R, et al. CCR7 coordinates the primary immune response by establishing functional microenvironments in secondary lymphoid organs. Cell. 1999;99(1):23-33.

32. Gunn MD, et al. Mice lacking expression of secondary lymphoid organ chemokine have defects in lymphocyte homing and dendritic cell localization. J Exp Med. 1999;189(3):451-460.

33. Ohl L, et al. CCR7 governs skin dendritic cell migration under inflammatory and steady-state conditions. Immunity. 2004;21(2):279-288.

34. MartIn-Fontecha A, et al. Regulation of dendritic cell migration to the draining lymph node: impact on T lymphocyte traffic and priming. J Exp Med. 2003;198(4):615-621.

35. Bradley MN, Tontonoz P. Lesion macrophages are a key target for the antiatherogenic effects of LXR agonists. Arterioscler Thromb Vasc Biol. 2005;25(1):10-11.

36. Zelcer N, Tontonoz P. Liver X receptors as integrators of metabolic and inflammatory signaling. J Clin Invest. 2006;116(3):607-614.

37. Fievet C, Staels B. Liver X receptor modulators: effects on lipid metabolism and potential use in the treatment of atherosclerosis. Biochem Pharmacol. 2009;77(8):1316-1327.

38. Levin N, et al. Macrophage liver X receptor is required for antiatherogenic activity of LXR agonists. Arterioscler Thromb Vasc Biol. 2005;25(1):135-142.

39. Bischoff ED, et al. Non-redundant roles for LXRalpha and LXRbeta in atherosclerosis susceptibility in low density lipoprotein receptor knockout mice. J Lipid Res. 2010;51(5):900-906.

40. Joseph SB, et al. LXR-dependent gene expression is important for macrophage survival and the innate immune response. Cell. 2004;119(2):299-309.

41. Tacke F, et al. Monocyte subsets differentially employ CCR2, CCR5, and CX3CR1 to accumulate within atherosclerotic plaques. J Clin Invest. 2007;117(1):185-194

42. Tacke F, Ginhoux F, Jakubzick C, van Rooijen N, Merad M, Randolph GJ. Immature monocytes acquire antigens from other cells in the bone marrow and present them to $\mathrm{T}$ cells after maturing in the periphery. J Exp Med. 2006;203(3):583-597.

43. Randolph GJ. Emigration of monocyte-derived cells to lymph nodes during resolution of inflammation and its failure in atherosclerosis. Curr Opin Lipidol. 2008;19(5):462-468.

44. Shen Z, Reznikoff G, Dranoff G, Rock KL. Cloned dendritic cells can present exogenous antigens on both MHC class I and class II molecules. J Immunol. 1997;158(6):2723-2730.

45. Quinet EM, et al. Liver X receptor (LXR)-beta regulation in LXRalpha-deficient mice: implications for therapeutic targeting. Mol Pharmacol. 2006;70(4):1340-1349.

46. Castrillo A, et al. Crosstalk between LXR and tolllike receptor signaling mediates bacterial and viral antagonism of cholesterol metabolism. Mol Cell. 2003;12(4):805-816

47. Castrillo A, Tontonoz P. Nuclear receptors in macrophage biology: at the crossroads of lipid metabo- lism and inflammation. Annu Rev Cell Dev Biol. 2004;20:455-480

48. Verschuren L, de Vries-van der Weij J, Zadelaar S, Kleemann R, Kooistra T. LXR agonist suppresses atherosclerotic lesion growth and promotes lesion regression in ApoE*3Leiden mice: time course and potential mechanisms. J Lipid Res. 2009;50(2):301-311.

49. Tangirala RK, et al. Identification of macrophage liver $\mathrm{X}$ receptors as inhibitors of atherosclerosis Proc Natl Acad Sci U S A. 2002;99(18):11896-11901.

50. Feig JE, Ma Y, Randolph GJ, Torra IP, Garabedian MJ, Fisher EA. CCR7 is functionally required for atherosclerosis regression and is activated by LXR. Arterioscler Thromb Vasc Biol. 2006;26:e-50.

51. Le Naour F, et al. Profiling changes in gene expression during differentiation and maturation of monocyte-derived dendritic cells using both oligonucleotide microarrays and proteomics. J Biol Chem. 2001;276(21):17920-17931.

52. Geyeregger $\mathrm{R}$, et al. Liver $\mathrm{X}$ receptors regulate dendritic cell phenotype and function through blocked induction of the actin-bundling protein fascin. Blood. 2007;109(10):4288-4295.

53. Tacke F, Randolph GJ. Migratory fate and differentiation of blood monocyte subsets. Immunobiology. 2006;211(6-8):609-618.

54. Zhou J, et al. Hepatic fatty acid transporter Cd36 is a common target of LXR, PXR, and PPARga$\mathrm{mma}$ in promoting steatosis. Gastroenterology. 2008;134(2):556-567.

55. Repa JJ, et al. Regulation of absorption and ABC1mediated efflux of cholesterol by RXR heterodimers. Science. 2000;289(5484):1524-1529.

56. Costet P, Luo Y, Wang N, Tall AR. Sterol-dependent transactivation of the $\mathrm{ABC} 1$ promoter by the liver X receptor/retinoid X receptor. J Biol Chem. 2000;275(36):28240-28245.

57. Schuster GU, et al. Accumulation of foam cells in liver $X$ receptor-deficient mice. Circulation. 2002; 106(9):1147-1153.

58. Schwartz K, Lawn RM, Wade DP. ABC1 gene expression and ApoA-I-mediated cholesterol efflux are regulated by LXR. Biochem Biophys Res Commun. 2000;274(3):794-802.

59. Mak PA, et al. Regulated expression of the apolipoprotein E/C-I/C-IV/C-II gene cluster in murine and human macrophages. A critical role for nuclear liver X receptors alpha and beta. J Biol Chem. 2002;277(35):31900-31908

60. Venkateswaran A, Repa JJ, Lobaccaro JM, Bronson A, Mangelsdorf DJ, Edwards PA. Human white/murine ABC8 mRNA levels are highly induced in lipid-loaded macrophages. A transcriptional role for specific oxysterols. J Biol Chem. 2000;275(19):14700-14707.

61. Peet DJ, et al. Cholesterol and bile acid metabolism are impaired in mice lacking the nuclear oxysterol receptor LXR alpha. Cell. 1998;93(5):693-704.

62 . Schultz JR, et al. Role of LXRs in control of lipogenesis. Genes Dev. 2000;14(22):2831-2838.

63. Bradley MN, et al. Ligand activation of LXR beta reverses atherosclerosis and cellular cholesterol overload in mice lacking LXR alpha and apoE. J Clin Invest. 2007;117(8):2337-2346.

64. Whitney KD, et al. Liver X receptor (LXR) regulation of the LXRalpha gene in human macrophages. J Biol Chem. 2001;276(47):43509-43515.

65. Lund EG, et al. Different roles of liver X receptor alpha and beta in lipid metabolism: effects of an alphaselective and a dual agonist in mice deficient in each subtype. Biochem Pharmacol. 2006;71(4):453-463.

66. Zelcer N, et al. Attenuation of neuroinflammation and Alzheimer's disease pathology by liver $x$ receptors. Proc Natl Acad Sci U S A. 2007;104(25):10601-10606.

67. Hume DA. Macrophages as APC and the dendritic cell myth. J Immunol. 2008;181(9):5829-5835.

68. Villablanca EJ, et al. Tumor-mediated liver X receptor-alpha activation inhibits CC chemokine receptor-7 expression on dendritic cells and dampens antitumor responses. Nat Med. 2010;16(1):98-105.

69. Wang G, Uludag H. Recent developments in nanoparticle-based drug delivery and targeting systems with emphasis on protein-based nanoparticles. Expert Opin Drug Deliv. 2008;5(5):499-515.

70. Rensen PC, et al. Selective targeting of liposomes to macrophages using a ligand with high affinity for the macrophage scavenger receptor class A. Curr Drug Discov Technol. 2006;3(2):135-144.

71. Mulder WJ, Fayad ZA. Nanomedicine captures cardiovascular disease. Arterioscler Thromb Vasc Biol. 2008;28(5):801-802.

72. Hajitou A, Pasqualini R, Arap W. Vascular targeting: recent advances and therapeutic perspectives. Trends Cardiovasc Med. 2006;16(3):80-88.

73. Manjunath $\mathrm{N}$, et al. Effector differentiation is not prerequisite for generation of memory cytotoxic $\mathrm{T}$ lymphocytes. J Clin Invest. 2001;108(6):871-878.

74. O'Neill DW, Bhardwaj N. Differentiation of peripheral blood monocytes into dendritic cells. Curr Protoc Immunol. 2005; Chapter 22:Unit 22F.4.

75. Houck KA, et al. T0901317 is a dual LXR/FXRagonist. Mol Genet Metab. 2004;83(1-2):184-187.

76. Shenoy SD, et al. CYP3A induction by liver $x$ receptor ligands in primary cultured rat and mouse hepatocytes is mediated by the pregnane $\mathrm{X}$ receptor. Drug Metab Dispos. 2004;32(1):66-71.

77. Trogan E, Choudhury RP, Dansky HM, Rong JX, Breslow JL, Fisher EA. Laser capture microdissection analysis of gene expression in macrophages from atherosclerotic lesions of apolipoprotein E-deficient mice. Proc Natl Acad Sci U S A. 2002;99(4):2234-2239.

78. Li AC, et al. Differential inhibition of macrophage foam-cell formation and atherosclerosis in mice by PPARalpha, beta/delta, and gamma. J Clin Invest. 2004:114(11):1564-1576.

79. Rong JX, Shapiro M, Trogan E, Fisher EA. Transdifferentiation of mouse aortic smooth muscle cells to a macrophage-like state after cholesterol loading. Proc Natl Acad Sci U S A. 2003;100(23):13531-13536.

80. Oxelmark E, Roth JM, Brooks PC, Braunstein SE, Schneider RJ, Garabedian MJ. The cochaperone p23 differentially regulates estrogen receptor target genes and promotes tumor cell adhesion and invasion. Mol Cell Biol. 2006;26(14):5205-5213. 